\title{
An Investigation Of Thermal Comfort Conditions Under Rock Formations in Sri Lanka
}

\author{
D.M.N.I. Gunadasa
}

\begin{abstract}
Behaviour of a rock as a barrier of heat differs so much from the behaviour of a conventional insulator. In thecase of an insulator the factor that governs the heat exchange is Thermal Conductivity. But rocks, being massive in both density and scale, the Heat Capacity of the material largely effect the heat flow. And under natural thermal environment, the heat flow will never reach a steady state. The governing factor of heat flow here is Thermal Diffusivity. This ever-transient heat flow problem is so complex that it is hardly studied. This report is the forerunner to a research or the capability to utilize natural rock for motions in architecture to create advanced thermal environment. The main objective is to verify whether rocks do effect the thermal environment of their surrounding to a level worthwhile to be studied.
\end{abstract}

\section{INTRODUCTION}

In tropical countries like Sri Lanka it can be seen that people find the interior of buildings too warm and humid. It is unusual for those whose evolution has been taken place in the same climate through thousands of years, to feel uncomfortable in the same climate. Only a little change of the basic parameters of climate such as mean temperature, humidity and annual rainfall ras taken place within the time duration of human evolution. Therefore it is likely that this discomfort is due to the nature of living spaces and the thermal properties of the materials used in modern buildings. The absence of trees also may have an effect on reducing thermal comfort today.

Rocks are elements closely related to human life from the beginning of human civilization. Their effect on formation of human cognition - in formation of the concept of home (rock caves), beliefs, religion and feelings of awe and respect is enormous. Looking at a rock one can perceive things beyond its physical existence rocks have instinctive meanings. There is the possibility to use rocks as strong architectural elements that evoke instinctive references once laid deep in human mind.

Natural rock caves were the earliest living spaces used by human beings. Spaces among rocks have been converted to living spaces in Sri Lankan meditation centers and temples of early days. These conversions seem to work well from the point of view of thermal comfort. These facts lead us to think about the possibility of integration of rocks to contemporary $S_{i} i$ Lankan architecture in order to create better living spaces with better thermal comfort levels achieved with passive means.

Many rocky sites can be found in Sri Lanka that are ignored and considered as barren lands. There are stone pits that end up as useless ponds of dirty water.
The possibility of converting these places to habitable spaces is yet to be found out.

Therefore it was decided to check whether the so-called living spaces among rocks really have better comfort levels. Level of thermal comfort of some selected rock caves and spaces created among rocks are measured and compared with that of immediate surrounding. This is to examine whether or not rocks have potential to provide improved thermal comfort levels. The facts how and to what extent rocks have affected comfort levels or what is the exact or mean comfort level of individual space is beyond the scope of this study.

Measurements are carried out with a dry bulb and wet bulb thermometer. Measurements of the selected spaces and the immediate surroundings were taken simultaneously. These data are used to find out the level of thermal comfort of the places. We decided to use the Temperature-Humidity Index developed by Thom (1959) because in this method the level of comfort is indicated in a numerical value so that the comfort levels can be numerically compared.

\section{Back Ground}

Temperature-Humidity Index (THI) is defined thus

$\mathrm{THI}=0.72 \times(T D+T W)+40.6$

Where TD and TW are dry bulb and wet bulb temperatures respectively.

THI $<60-100 \%$ of the subjects felt uncomfortably cold. $60<\mathrm{TH}<65-50 \%$ of the subjects felt uncomfortable. $65<\mathrm{TH}=75-100 \%$ of the subjects felt comfortable. $75<\mathrm{THI}=80-50 \%$ of the subjects felt uncomfortable. $80<\mathrm{THI}-100 \%$ of the subjects felt uncomfortably hot. (cf. Deosthali, 1999)

These ranges are for universal application and may vary slightly when applied for Sri Lankans. 


\section{Case Studies}

Few sites in Kurunegala, Mihinthale and Anuradhapura were selected for the study. The sites essentially are of rock formations and have different forms that are of interest and variety.

Three sites are studied at Vessagiriya in Anuradhapura. First one of which is a cave that have openings to both east and west directions. The west side of which is a courtyard surrounded by rocks. The place named here, as Vessagiriya cave $B$ is an inward protrusion of a rock facing east. The western side of this rock on which the morning shadow of the rock falls, is also of interest. Vessagiriya cave $\mathrm{C}$ is a well covered cave facing south. There is only one opening to the cave and it is protected by direct sunlight from east and west directions due to two walls of rock and few trees. This cave too faces a rock-guarded courtyard.

The caves of Dambulla temple consist of a series of caves that opens to west and the largest one of them was selected for the study. The entrance to the cave is protected by two walls with a balcony in between them. Due to these walls less air movement is allowed and it feels that the air inside is trapped. The compound of the cave is well protected from morning sun due to the shadow of the rock. Steady and strong wind blows across the compound.

Three sites in Mihinthale are studied. One of them, the Mihindo cave, is situated at a higher elevation and is open from both north and south directions. Therefore high winds blow across the cave. The place referred to as open cave is a place surrounded by tall slabs like formations of rocks. rocks seems to be converging to a point above. The cave is bare headed and daylight freely comes into the cave. Due to few narrow openings between rocks, wind blows almost freely across the cave. Mihinthale rock top (aradana gala) is the third place studied in Mihinthale and the intension of study is to find out the effect of horizontal rock surface alone on thermal comfort. Kurunegala rock too has the same kind of rock environment. Therefore these two studies of rock tops are done with almost similar intensions.

\section{RESULTS}

\section{Thermal comfort level of Vessagiriya cave $A$}

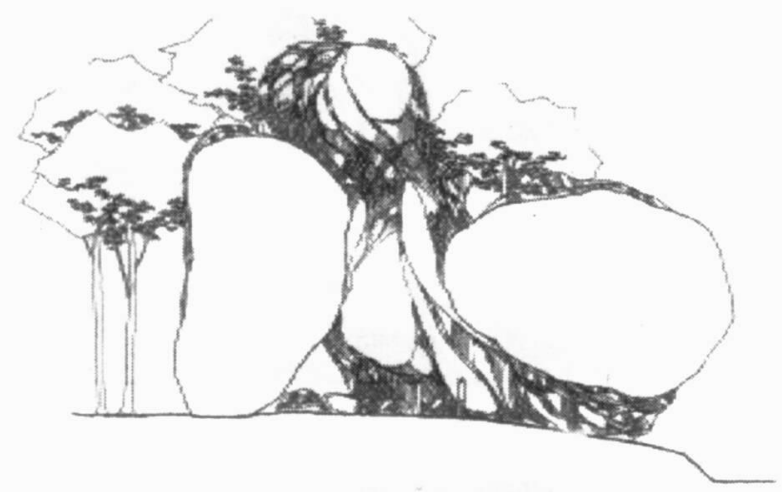

Section through vessagiriyacave $A$

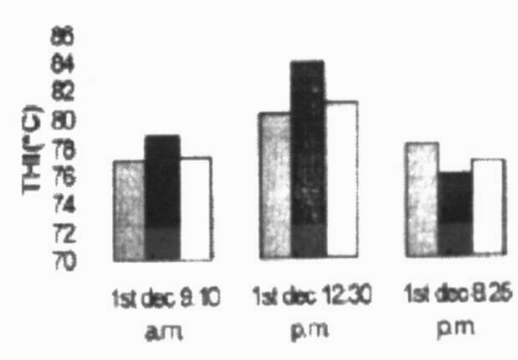

Dinsice

Eatsice oxt

Datsce west

Figure1: Vessagiriya cave A THI values

The cave was open from both east and west directions bare land (only grass) to the east and a courtyard surrounded by rocks to the west.

THI values shown in above chart indicate that inside the cave the level of comfort tends to stay constant in relation to the outside. The level of comfort inside the cave almost stays within the range of $75-80$ where it is said to be $50 \%$ comfortable. At night outside conditions seems to be more comfortable than inside.

\section{Thermal comfort level of Vessagiriya cave $B$}

The place that is referred here as cave $B$ is just a jutting out of a rock to the east to which the morning sun penetrates. The rock has an enormous height that it shades the west side till noon. Both the east and west ends of the place are well open to the sky and are bare land with rocks and grass.

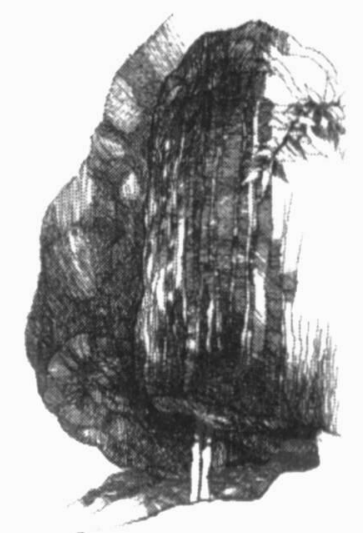

Side elevation of vessagiriya cave B

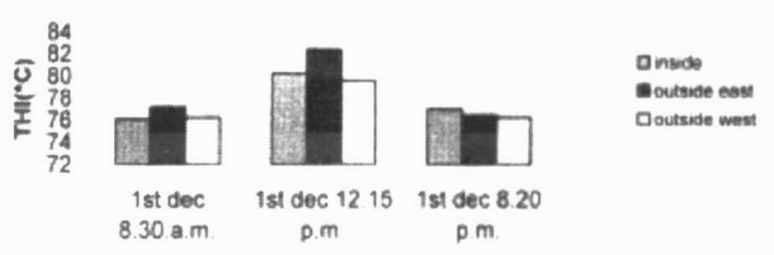

Figure 2: THI Values of V Vessagiriya cave B 
The results indicate that it is the western side, which was well protected from solar radiation from morning to noon, is the most comfortable. The eastern side, which is shaded from noon to evening, shows a violent variation of the level of comfort and seems to be the most uncomfortable. However it seems that at night the outside conditions are more comfortable but it cannot be said that the interior is not comfortable.

\section{Thermal comfort level of Vessagiriya cave $C$}

The cave faces south and is open only from one side. Cave has a front courtyard, which too is surrounded by rocks. There is only a limited opportunity for wind to blow inside the cave so that the rate of air change is low.
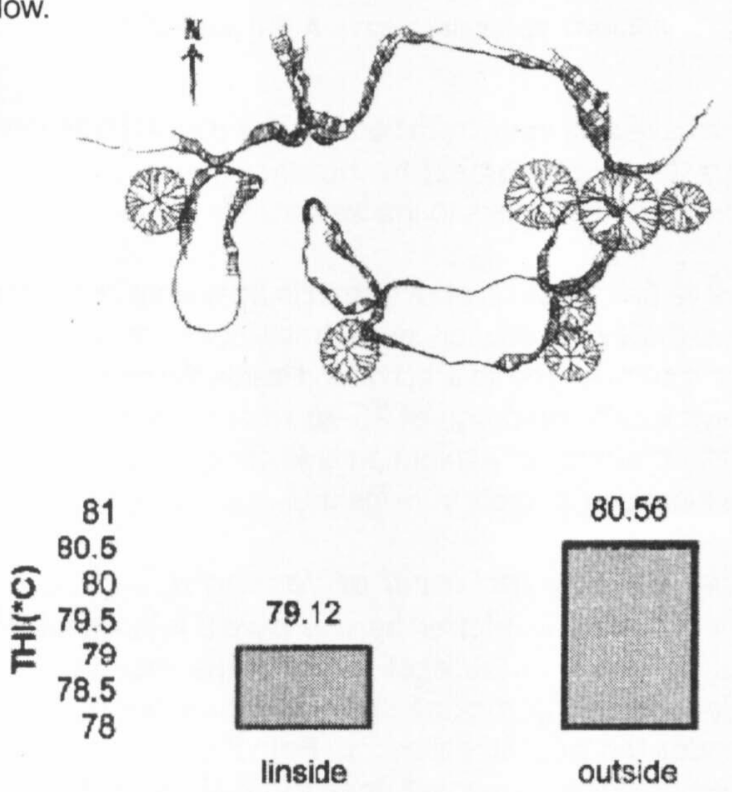

Figure 3

The results show that trapping air to avoid outside hot air coming in does not provide better thermal environment. Though the temperature inside the cave is considerably low than that of outside, the level of Relative Humidity is too high inside the cave due to entrapped air $(\mathrm{RH}$ inside is $80 \%$ and $\mathrm{RH}$ outside is $70 \%$ approximately).

However according to the data the interior of the cave seems comfortable than the outside.

\section{Thermal comfort of Mihindo cave Mihinthale}

The cave is situated in a higher elevation and is open from both sides of North and South. Blow of wind is strongly felt inside the cave through out the day. The space is very small and the penetration of the sun from side ways is considerable.

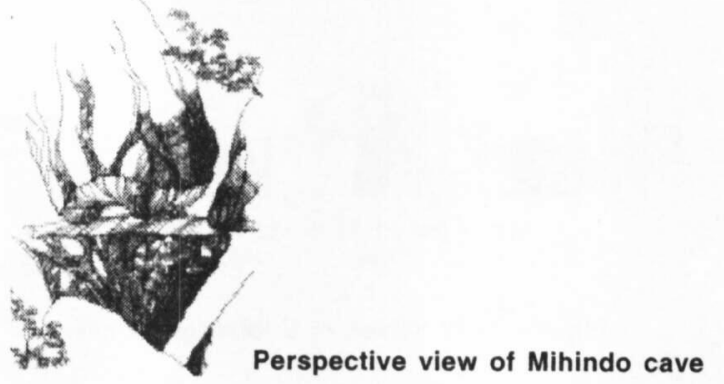

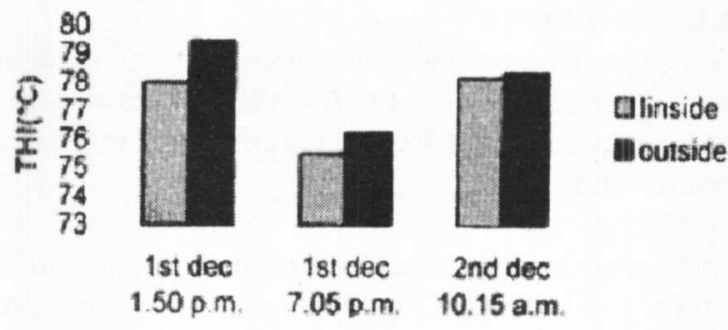

Figure $4 \mathrm{THI}$ values of Mihindu cave

The immediate outside location at which the outside thermal data were taken was at a lower elevation and considerably shaded by trees and the shadow of the rock. The blow of wind is relatively low.

Results show that the interior of the cave is comfortable then outside. However the difference is not that much.

\section{Thermal comfort of open cave Mihinthale}

This space made among rocks was found near the Mihindo cave. The space is of interest because it is well covered from sideways leaving few narrow gaps in between through which the blow of wind is invited to the interior. There is no cover above and therefore it is open to the sky. Sun penetrates only at mid day.

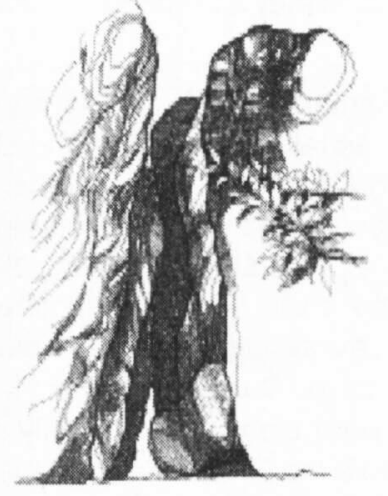

Front elevation of Mihindo open cave

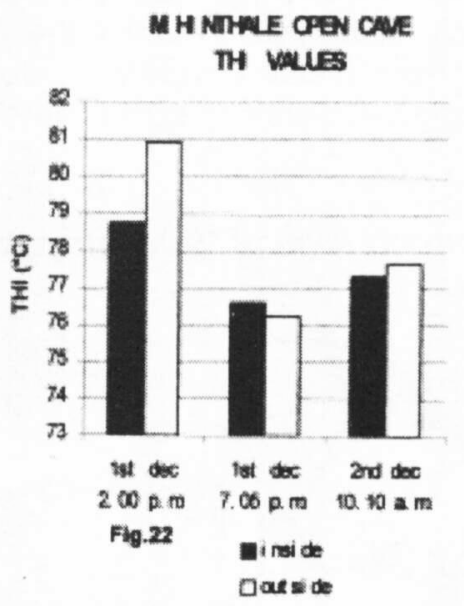

Figure 5 THI values of Mihinthale open cave

The results show that the level of comfort within the space tends to stay constant in relation to the outside conditions. The interior is comfortable even at 2.00 p.m. around which the highest level of discomfort can be expected. 


\section{Thermal comfort at Dambulla cave in Dambulla temple}

Inside the cave it is felt that the air is trapped and there is only a little air movement. Lot of moisture gets into to the inside air due to constant visit of people. And lot of heat is generated inside by electric lamps.

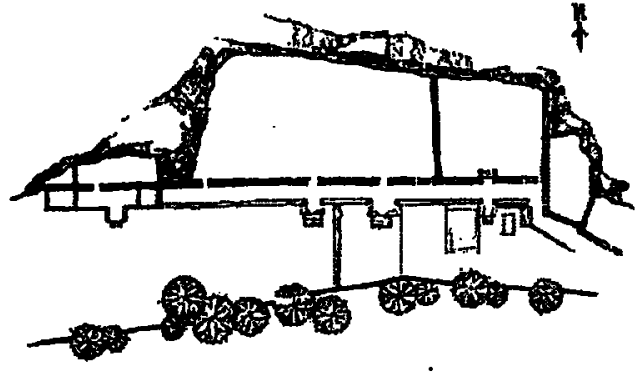

Plan of Dambulla cave
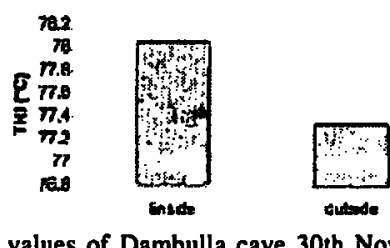

THI values of Dambulla cave 30th November at 1.00 p.m.

Figure 6 THI values In Dambulla cave

The results indicate that inside the cave is more uncomfortable than the surroundings. This reminds that trapping air and generating heat and moisture inside shall bring worst conditions inside a tropical building. However it is agreed that the result is a draw back to the study.

\section{Thermal comfort Mihinthale rock top and Kurunegala rock top}

THI VALUES OF MIHINTHALE ROCK
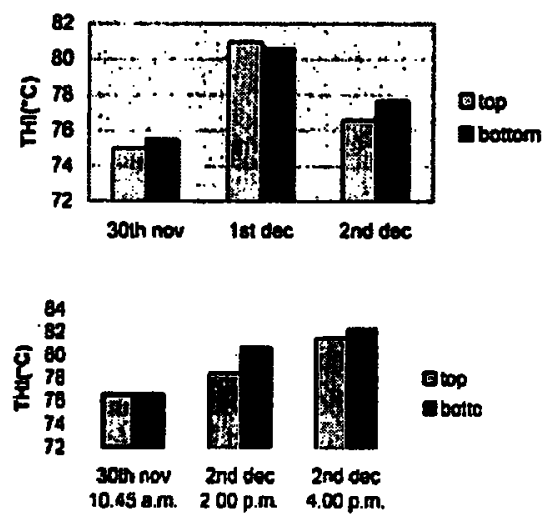

Figure 7 THI values of Kurunegala rock

Thermal comfort levels of these summits were decided to consider as examples of spaces where ground surface is out of rock. The conditions were compared with that of places of nomal ground at immediate outside. Discomfort level at $1^{\text {s }}$ December 1.30 p.m. at Mihinthale rock top is higher than that of outside. This is because the outside location at which the readings were taken was shaded by the shadow of the rock at the time at which the reading was taken. In all other cases the data clearly shows that rock tops are themally comfortable than normal grounds.

\section{5: DISCUSSION}

Despite $30^{\text {th }}$ November at 10.45 a.m. at kununegala, all other data were taken under good weather conditions and under almost clear skies. On $30^{\text {th }}$ November at 10.45 a.m. in kurunegala at the rock top, sky was overcastted and it was about to rain. The data at rock bottom was taken while it was slightly raining.

In this study different types of spaces created among rocks were taken into consideration; spaces totally covered by rocks, covered only from side ways, covered from one side etc. in almost all the cases it was clearly shown that the considered spaces to be comfortable than its immediate outside. Vessagiriya cave $C$ is a place that is well covered by rocks and was found to be comfortable in almost mid day while outside conditions were found to be uncomfortable. Thermal comfort levels of Vessagiriya cave $B$, east to the cave $B$ and west to the cave $B$ differs very much from each other proving the capability of rocks to moderate thermal comfort. Again in the case of Vessagiriya cave A, the THI values of inside differs to that of outside and tries to stay within the range of 75-80 through out the day while the TH values of out side conditions showing a variation of a greater deviation. In the case of Mihindo cave at Mihinthale, the inside conditions were found to be more comfortable than the conditions of the surrounding environment, which is shaded better than the interior of the cave. Mihinthale open cave too shows better thermal comfort levels in relation to its surrounding except at night. The THI values of inside show only a little deviation. Study of rock tops too shows clear differences of THI values.

\section{CONCLUSION}

This study, therefore, clearly indicates that rocks definitely can effect to modity thermal comfort properties of a space. For instance a rock may cut off thermal radiation of the sun completely and the heating up of its outer surface will have almost no effect on the temperature of its interior surface. The use of a rock roof may be effective in relation to any other traditional roof and will cut off the thermal effect of the sun completely during daytime. However to declare an art of using properties and thermal behavior of rock in creation of thermally comfortable spaces and in such a case, to predict the practically achievable level of comfort, more vivid and scientific tests have to be carried out.

\section{References:}

Billington $\mathbf{N}$. Thermal properties of buildings cleaner hume, London 1952

Mason R. Petrology of meta morphic Rocks. Unwin Brolhers Lid. Great Britain 1978

Somerton W.H. Thermal properties and tenperature related behaviour of Rak/ Fleid systems elsevies, Amsterdam 1992 